\title{
Use of Pyruvate-Phosphate Dikinase as a Target for Herbicide Design: Analysis of Inhibitor Specificity
}

\author{
Arthur L. Lawyer, Sarita R. Kelley, and Judith I. Allen \\ Biotechnology Group, Chevron Chemical Company, Ortho Research Center, \\ P. O. Box 4010, Richmond, CA 94804-0010, USA \\ Z. Naturforsch. 42c, 834-836 (1987); received December 5, 1986 \\ Pyruvate-Phosphate Dikinase, Phosphoenolpyruvate Carboxylase, $\mathrm{C}_{4}$-Photosynthesis, Herbicide \\ Design, Inhibitor Specificity. \\ Pyruvate-phosphate dikinase (PPDK) was targeted for inhibitor design because of its central \\ role in $\mathrm{C}_{4}$-type photosynthetic carbon metabolism and its relative absence in $\mathrm{C}_{3}$-type plants and \\ organisms of the animal kingdom. Compounds were tested for their activities as reversible and \\ irreversible inhibitors of PPDK isolated from maize. The relative activity of the test compounds \\ against phosphoenolpyruvate carboxylase (PEPCase), isolated from wheat, was used as a meas- \\ ure of the specificity of the inhibitors for the targeted enzyme, PPDK. An ideal compound for \\ successful herbicide design should be an inhibitor which is specific toward the targeted enzyme \\ and either effectively inhibits enzyme activity at very low concentrations or inactivates the enzyme \\ through an irreversible mechanism. Using results obtained with commercially purchased com- \\ pounds, the discussion will emphasize the difficulty of obtaining specific inhibitors toward PPDK. \\ Another report from this laboratory (A. L. Lawyer, S. R. Kelley, and J. I. Allen, in: Proc. \\ Seventh Internat. Congr. Photosynth. (J. Biggins, ed.), in press) emphasizes other results ob- \\ tained from the targeting of PPDK for herbicide activity.
}

\section{Introduction}

Pyruvate-phosphate dikinase (PPDK) was used as the target enzyme for the design of herbicides selective for plants with $\mathrm{C}_{4}$-type photosynthetic carbon metabolism. This paper will summarize one of the major difficulties encountered in developing successful herbicides from inhibitors of the targeted enzyme.

PPDK was chosen as a promising site for herbicide action for several reasons. As an enzyme central to $\mathrm{C}_{4}$-type photosynthetic carbon metabolism, inhibition of PPDK should lead to the death of $\mathrm{C}_{4}$-type plants. On the contrary, $\mathrm{C}_{3}$-type plants have relatively little PPDK $[2,3]$ and the importance of PPDK to $\mathrm{C}_{3}$-plants is unknown. Therefore, a specific inhibitor of PPDK should result in a herbicidal spectrum selective for $\mathrm{C}_{4}$-type plants. Since most of the major grassy weeds are $\mathrm{C}_{4}$-plants and most economically important grassy crops are $\mathrm{C}_{3}$-plants, the search for specific inhibitors of PPDK could be justified. Finally, most species of the animal kingdom do not possess PPDK activity. We assumed, therefore, that inhibitors specific to PPDK might be expected to have inherently low toxicity toward animals.

Reprint requests to Dr. A. L. Lawyer.

Verlag der Zeitschrift für Naturforschung, D-7400 Tübingen $0341-0382 / 87 / 0600-0834 \$ 01.30 / 0$
An ideal enzyme inhibitor which can lead to successful activity as a commercial herbicide with low potential for toxicity and low use rates in the field should be both specific toward the targeted enzyme and, if possible, effective at low concentrations. Effectiveness at low concentrations can be accomplished through either a strong binding affinity of the inhibitor (low $K_{\mathrm{i}}$ value) or an inhibitor which acts via an irreversible mechanism. Unfortunately, there are nearly a dozen enzymes which utilize pyruvate as a substrate and are crucial to carbon metabolism. Many of these enzymes are common to all living organisms. Due to the relatively small size of pyruvate and the numerous enzymes which could be inhibited by pyruvate analogs, the targeting of PPDK for herbicide design has inherent difficulties. Though the enzyme-bound phosphate intermediate invoked in the catalytic mechanism of PPDK $[4,5]$ is unique to pyruvate-utilizing enzymes and a cystidyl group is purportedly located in the active site [6], these factors do not necessarily make the search for an inhibitor specific to PPDK any easier.

Specific inhibitors mimicking small substrates do exist and can possess herbicidal activity. The herbicide glyphosate mimics an enolpyruvyl intermediate in the mechanism of enolpyruvylshikimate-phosphate synthase. However, the difficulty in obtaining this kind of specificity with a small inhibitor is illus- 
trated by the fact that no analogs of glyphosate have ever been found that have similar activity.

In our attempts to develop inhibitors of PPDK, both the reversible and irreversible activities of test compounds toward PPDK were measured. In addition, the specificity of inhibition toward PPDK was examined by measuring the inhibition of phosphoenolpyruvate carboxylase (PEPCase) by test compounds. This report describes the results obtained from these specificity tests, using test compounds which were purchased commercially. The difficulties encountered in obtaining specific inhibitors, including those possessing irreversible activity, will be discussed.

\section{Materials and Methods}

Details of the methods used for the evaluation of PPDK inhibitors are described elsewhere [1].

Partially purified PPDK from 3 week old maize (Bantam Golden Cross) was used. Maize leaves $(50 \mathrm{~g})$ were homogenized, filtered, centrifuged and placed directly onto a DEAE-cellulose column. PPDK, free of contaminating PEPCase activity, was eluted with a salt gradient and concentrated. The specific activity of this PPDK was about 2 units/mg protein.

PPDK activity was followed spectrophotometrically by coupling phosphoenolpyruvate production to
PEPCase and malate dehydrogenase activities. Typical assays contained 100 mм HEPES buffer, pH 8.0, $5 \mathrm{~mm}$ DTT, $10 \mathrm{~mm} \mathrm{MgSO}_{4}, 2.5 \mathrm{~mm} \mathrm{~K}_{2} \mathrm{HPO}_{4}, 50 \mathrm{~mm}$ $\mathrm{NaHCO}_{3}, 5 \mathrm{~mm}$ glycine, $5 \mathrm{~mm}$ glucose-6-phosphate, $330 \mu \mathrm{m}$ NADH, 1.25 mм ATP, 2.5 units malate dehydrogenase (porcine heart, Calbiochem), 4 units PEPCase (wheat, Boehringer-Mannheim), and 0.033 units of PPDK in a final volume of $1.0 \mathrm{ml}$ at $25^{\circ} \mathrm{C}$.

The concentrations and conditions used for measuring PEPCase activity were identical to those described above for PPDK except that only 0.8 unit of PEPCase was used and ATP was eliminated from the assays.

\section{Results and Discussion}

The range of inhibition constants $\left(K_{\mathrm{i}}\right.$ 's) toward PPDK activity is shown in Table I. The $K_{\mathrm{i}}$ values shown were determined for compounds purchased commercially using Dixon-type analyses (1/v vs. [I]) assuming that the inhibitors acted competitively with respect to the substrate, pyruvate. The $K_{\mathrm{i}}$ values ranged from 100 -fold tighter binding than that for the natural substrate, pyruvate $\left(K_{\mathrm{m}}=220 \pm 120 \mu \mathrm{M}\right)$, to several-fold weaker than the substrate. As discussed elsewhere [1], the binding affinities improved with halogenation at the 3-position.

The specificity of the inhibitors toward PPDK was tested by measuring their relative affinity toward

Table I. Inhibition of pyruvate phosphate dikinase and phophoenolpyruvate carboxylase by commercially available compounds.

\begin{tabular}{|c|c|c|c|c|c|}
\hline \multirow[t]{2}{*}{ Compound name } & \multicolumn{5}{|c|}{ Inhibition constant $\left(K_{\mathrm{i}}\right)$} \\
\hline & \multicolumn{2}{|c|}{$\begin{array}{l}\text { PPDK } \\
\mu \mathrm{M} \pm \text { std. err. }\end{array}$} & \multicolumn{3}{|c|}{$\begin{array}{l}\text { PEPCase } \\
\mu \mathrm{M} \pm \text { std. err. }\end{array}$} \\
\hline Methyl-2,4-diketo- $n$-pentanate & 1.7 & 0.4 & $1.5=$ & & 0.4 \\
\hline 3-Indolepyruvic acid monohydrate & 4.8 & 0.8 & $<5$ & & \\
\hline 3-Indoleglyoxylic acid & 18 & 2 & $<20$ & & \\
\hline Ethyl-3-trichloropyruvate & 46 & \pm & 2,100 & \pm & 100 \\
\hline 3-Bromopyruvic acid & 290 & 70 & 3,200 & \pm & 1,600 \\
\hline 3-Fluoropyruvic acid & 330 & 60 & 2,400 & \pm & 500 \\
\hline 2-Phenylglyoxylic acid sodium salt & 990 & 200 & 610 & \pm & 290 \\
\hline Ethyl-4-chloroacetoacetate & 1,400 & 200 & n.d. & & \\
\hline 2-(Bromomethyl)-acrylic acid & 3,900 & $\pm \quad 100$ & n.d. & & \\
\hline Ethyl-2,3-dibromoproprionate & 11,000 & $\pm 3,000$ & 7,200 & \pm & 3,200 \\
\hline 3-Dimethylpyruvate sodium salt & 35,000 & $\pm 14,000$ & 180,000 & \pm 18 & 80,000 \\
\hline Ethyl-1-piperidine-glyoxylate & 41,000 & $\pm 30,000$ & 12,000 & \pm & 7,000 \\
\hline
\end{tabular}

Inhibition constants were determined from Dixon analyses $(1 / \mathrm{v} v s$. [I] ) assuming binding is competitive relative to the substrate, phophoenolpyruvate. Substrate levels used for the analyses were about the $K_{\mathrm{m}}$.

n.d. = not determined. 
PEPCase from wheat. The $K_{\mathrm{i}}$ values obtained for PEPCase are listed in Table I. As observed with inhibitor binding to PPDK, the compounds ranged in their activity from several-fold above to several-fold below the $K_{\mathrm{m}}$ value for the natural substrate, phosphoenolpyruvate $\left(K_{\mathrm{m}} \approx 100 \mu \mathrm{M}\right)$.

Strong specificity of inhibitors toward PPDK activity relative to PEPCase activity was never observed with any of the compounds tested by this laboratory. This included both compounds purchased commercially (Table I) and compounds synthesized for this project (data not shown). Table I illustrates that most compounds inhibited the two enzymes fairly equivalently. The best specificity was obtained with ethyl-3-trichloropyruvate, which favored PPDK 46-fold. The strongest inhibitors were all nonspecific toward PPDK.

The results obtained with the specificity test, in retrospect, are not surprising. It should be difficult to design specific inhibitors for enzymes which use substrates of low molecular weight such as pyruvate and phosphoenolpyruvate. In addition, these substrates

[1] A. L. Lawyer, S. R. Kelley, and J. I. Allen, in: Proc. Seventh Internat. Congr. Photosynth. (J. Biggins, ed.), in press (1986).

[2] K. Aoyagi and J. A. Bassham, Plant Physiol. 80, 334-340 (1986).

[3] K. Aoyagi and J. A. Bassham, Plant Physiol. 75, 387-392 (1984). are common metabolites and central to carbon metabolism. They are used by over a dozen different enzymes. Even though PPDK is unique to pyruvateutilizing enzymes in its use of an enzyme-bound phosphate moiety during catalysis $[4,5]$, the development of inhibitors specific toward PPDK activity still proved to be elusive.

The project for developing $\mathrm{C}_{4}$-specific herbicides was terminated for several reasons. It was determined that inhibitors with adequate specificity toward PPDK would be hard to find due to the reasons discussed above. In addition, the ability to design chemical reactivity into inhibitors of PPDK (building irreversible inhibitors) was limited due to the size constraints put upon the inhibitors.

In conclusion, though the selection of PPDK for herbicide design was a logical choice based on physiological and comparative biochemical grounds, the targeting of PPDK fell short on the basis of substrate size limitations and inability to find unique aspects in PPDK's catalytic mechanism which could differentiate it from other pyruvate-utilizing enzymes.

[4] N. F. B. Phillips, N. H. Goss, and H. G. Wood, Biochem. 22, 2518-2523 (1983).

[5] N. F. B. Phillips and H. G. Wood, Biochem. 25, 1644-1649 (1986).

[6] H. Yoshida and H. G. Wood, J. Biol. Chem. 253, 7650-7655 (1978). 